sleeping and vomiting was referred to our emergency to undergo a brain CT scan. CT images demonstrated a welldefined, rounded, hyper-dense lesion at the level of the foramen of Monro causing moderate dilatation of the lateral ventricle. The findings from imaging perspective were consistent with the colloid cyst of the third ventricle. Therefore, the diagnosis of the colloid cyst was made.

Early detection and total excision of the lesion is a permanent cure with minimum morbidity.

\section{P655 MOYA MOYA IN CHILDREN: ABOUT 2 CASES}

${ }^{1}$ Faiza Safi, ${ }^{1}$ Sahar Trichilli, ${ }^{1}$ Lamia Gargouri, ${ }^{2}$ Chiraz Regaieg*, 'Manel Hsairi, ${ }^{2}$ Abdellatif Gargouri, ${ }^{1}$ Abdelmajid Mahfoudh. ${ }^{1}$ Pediatric Emergency and Resuscitation Pediatric Service, Hedi Chaker Hospital, Sfax, Tunisia; ${ }^{2}$ Neonatal Intensive Care Unit, Sfax, Tunisia

\subsection{6/archdischild-2019-epa.985}

Introduction Moya Moya is a rare chronic intracranial arterial disease that affects internal carotid arteries. It is characterized by a progressive occlusion of the end portions of the internal carotids with the development of a locum circulation.

Cases report Two cases of Moya Moya have been reported. They were a 9 years old male and a $6 \frac{1}{2}$ years old female. Both children had a history of ischemic stroke revealed in one case by right hemiparesis, and in the other case by transient bilateral blindness. The first child had a stroke in the left superficial sylvian artery at the age of 2.5 years, with no thrombogenic pathology or haemostasis disorder. He received an anti platelet aggregation and practiced motor rehabilitation. He consulted after 6 years for generalized tonic-clonic seizures with behavioral disorder and mental confusion. The angio MRI showed multiple systemic vascular accidents dealing with the diagnosis of Moya Moya. The second child had at the initial brain scan a recent occipital ischemic hypodensity with multiple porencephalic cavities probably sequellar in bi frontal and anterior arm of the right internal capsule. Then she reconsulted after 3 months for a recurrence of blindness associated with an alteration of the state of consciousness. A brain MRI showed the presence of multiple strokes of different ages. The diagnosis of Moya Moya was confirmed by cerebral palsy. Both children had severe sequelae.

Conclusion Moya Moya is a rare but serious chronic cerebrovascular disease in young children. The diagnostic delay is frequent, related to its polymorphous symptomatology. The diagnosis is based on Angio CT and Angio MRI brain which are requested in 1 st intention. It must be evoked in front of repetitive vascular accidents of children of different ages.

\section{P656 EVALUATING THE INFANT NUTRITION UNDER 2 YEARS OF AGE}

${ }^{1}$ Nisa Pekcan Bolukbasi*, ${ }^{1}$ Emel Gur, ${ }^{2}$ Gunay Can, ${ }^{1}$ Ahmet Tayyar Arvas. ${ }^{1}$ Istanbul University Cerrahpasa Medical Faculty, Department of Pediatrics, Istanbul, Turkey; ${ }^{2}$ Istanbul University Cerrahpasa Medical Faculty, Department of Public Health, Istanbul, Turkey

\subsection{6/archdischild-2019-epa.986}

Aim of this study was to evaluate the infant nutrition in the first 2 years of age, to determine the factors effecting nutrition, and reveal the relationship among nutrition with infant growth.
Material Method: The study was carried out between September-December in 2018 by Cerrahpasa Faculty of Medicine, Department of Pediatrics in Istanbul.297 infants included who were not diagnosed with any disease born above 2500 gram. Face-to-face survey method was applied to parents using the indicators of infant and young child feeding (1ycf) which was established by WHO in 2007 to evaluate breastfeeding and complementary feeding. Information about sociodemographic data was recorded in the same interview. Height and weight were taken by the trained outpatient clinic and according to the WHO growth curves, weight according to age <-2SDS measured as underweight, height according to age $<-2$ SDS stunned and weight according to height $<-2$ SDS wasted.

Findings In the study, $52.5 \%$ were female while the rest were male. Infants age were between 15 days and 2 years. Initiating breastfeeding in the first hour was $25.6 \%$. Exclusive breastfeeding rate was $62.1 \%$. Breastfeeding up to 2 years of age rate was $60 \%$. In the study, $5.1 \%$ infant was wasted, $3 \%$ was stunned and $2 \%$ was underweight. According to the IYCF minimum meal diversity rate was $\% 62,3$, minimum meal frequency $72.7 \%$, minimum acceptable diet $62.3 \%$. Starting solid food appropriate was $\% 74$. If father was educated or an officer, the rate of breastfeeding was increasing for the first 6 months. It was found that babies whose father was younger than 30 years of age were more likely to breastfed in the first hour. Cesarean significantly reduced breastfeeding during the first 6 months and increased the rate of using bottles. Babies with birth order more than 3 were fed less with bottles. Breastfeeding in the first 6 months who's weighting less than $3000 \mathrm{~g}$ ratio were lower than others. If the number of children in the family were more than 3 wasting was higher. Breastfeeding babies up to 2 years of age were higher in whom born in a state hospital rather than private hospital. If the babies are male, rate of breastfeeding in the first 6 months and starting solid food suitability were higher. If maternal age was 30 or above minimum acceptable diet rate was higher.

Conclusion In our study nutrition rate according to WHO was majority this emphasizes the importance of educating the parents.

\section{P657 TO ESTABLISH PARENTAL PERCEPTION OF CHILDREN'S WEIGHT STATUS IN THOSE ATTENDING TEMPLE STREET CHILDREN'S UNIVERSITY HOSPITAL EMERGENCY DEPARTMENT}

Caitríona Loomes*, Laura Mannion, Cliona McGarvey, Sinéad Murphy. Temple Street Children's University Hospital, Dublin, Ireland

\subsection{6/archdischild-2019-epa.987}

Background A 2018 study based on the 'Growing Up in Ireland' data published by Queally $M$. et al. identified that approximately $22 \%$ and $18 \%$ of mothers failed to recognise that their child was overweight/obese at three and five years of age respectively.

Aims

1. To calculate the body mass index (BMI) of children attending the Temple Street Emergency Department using the 'Measure Me' phone application.

2. To establish parental perception of their child's weight status.

3. To Identify discrepancies between the subjective and objective weight status and communicate this to the parents. 
4. To provide educational information on healthy eating/further weight management options.

Methods Children aged two years or older attending the Emergency Department were identified. Parents completed a survey indicating the perceived weight status of their child. The height and weight of the child were recorded, and the BMI and standardised body mass index (BMI SDS) were calculated using the 'Measure Me' phone application and communicated to the parents. Children were offered a 'Healthy Ireland' food pyramid sticker. Parents of those overweight/ obese children identified were provided with details to be referred onto Temple Street Hospital Outpatient Services for further weight management.

Results 101 children in total participated. 17.8\% (18/101) were classified as overweight/obese, with a standardized BMI above the $91^{\text {st }}$ centile. Of those overweight/obese; 50\% $(9 / 18)$ of parents incorrectly identified their child to be of normal weight status. Of the parents who accurately identified their child as overweight (9/18), 77.8\% (7/9) indicated they perceived their child to be 'mildly' overweight. Objectively $85.7 \%(6 / 7)$ of these were obese with a BMI SDS above the $95^{\text {th }}$ centile. In total $83.3 \%(15 / 18)$ of the overweight children had a standardized BMI above the $95^{\text {th }}$ centile. $83.3 \%(15 / 18)$ of overweight/obese children accepted educational information. Conclusion In keeping with Queally M. et al.'s study a large proportion of children were objectively overweight/obese with a BMI SDS above the $91^{\text {st }}$ centile. However half of the parents failed to accurately identified their child's overweight/obese status. Although the remainder of parents accurately identified their child as overweight, a large proportion indicated that they perceived their child to be 'mildly overweight'. The vast majority of these children were obese with a BMI SDS above the $95^{\text {th }}$ centile. The high rates of parental acceptance of educational information would suggest a willingness to be further educated on weight optimization in children.

\section{P658 ASSOCIATION OF SEVERE VIRAL BRONCHIOLITIS DURING INFANCY AND EARLY LIFE WITH DEVELOPMENT OF RECURRENT WHEEZE}

Helena Živić*. Health facility Zagreb Center, Zagreb, Croatia

\subsection{6/archdischild-2019-epa.988}

Introduction Respiratory viral infections in infancy and early life, especially with allergic sensitization, are associated with higher risks of developing recurrent wheeze and asthma.

Objective To analyze the association of viral bronchiolitis in infancy and early life with development of recurrent wheeze.

Design and participants Retrospective study of children younger than 1 year, in our primary care setting, treated for bronchiolitis during 3 consecutive fall to winter seasons (2014-2016). Causative viruses of bronchiolitis were RSV and rhinovirus species. Development of recurrent wheeze (as defined in national asthma guidelines) by age 3 years.

Results 100 infants who were treated for RSV or rhinovirus bronchiolitis. The median age was 3 months (range 1-7 months), 42 (42\%) had RSV bronchiolitis, 58 (58\%) had rhinovirus bronchiolitis. $42(42 \%)$ had IgE sensitization, of which $14(33.3 \%)$ to food, $18(42.9 \%)$ to aeroallergens, $10(23.8 \%)$ to food and aeroallergens combined. Overall, 39 (39\%) developed recurrent wheeze by age 3 years. There was a significant interaction between viral bronchiolitis and $\operatorname{IgE}$ sensitization on the risk of recurrent wheeze. All children who developed recurrent wheeze also had $\mathrm{IgE}$ sensitization.

Conclusions Infants with both bronchiolitis and IgE sensitization (to food or aeroallergens) had significantly higher risks of recurrent wheeze with subsequent development of asthma at age 3 years. It identifies infants at higher risk so we can introduce preventive measures, and enhanced follow-up.

\section{P659 CORNELIA DE LANGE SYNDROME AND SPONTANEOUSLY REGRESSIVE BRONCHOGENIC CYST ABOUT A UNUSUAL CASE}

${ }^{1}$ Faiza Safi, ${ }^{1}$ Sahar Trichilli, ${ }^{1}$ Manel Hsairi, ${ }^{1}$ Lamia Gargouri, ${ }^{2}$ Chiraz Regaieg*, ${ }^{3}$ Mahdi Ben Dhaou, ${ }^{2}$ Abdellatif Gargouri, ${ }^{3}$ Riadh Mahiri, ${ }^{1}$ Abdelmajid Mahfoudh. ${ }^{1}$ Pediatric Emergency and Resuscitation Pediatric Service, Hedi Chaker Hospital, Sfax, Tunisia; ${ }^{2}$ Neonates Intensive Unit Care, Hedi Chaker Hospital, Sfax, Tunisia; ${ }^{3}$ Pediatric Surgery Department, Hedi Chaker Hospital, Sfax, Tunisia

\subsection{6/archdischild-2019-epa.989}

Introduction Cornelia de Lange syndrome is characterized by intra uterine and postnatal growth retardation, developmental disorder, facial dysmorphism, hypertrichosis, and organ malformations. The association with a bronchogenic cyst is unusual. Case report This is an 8-month-old male, born at term from a non-consanguineous marriage. He was hospitalized twice for recurrent pneumonitis. It was addressed for further exploration.On clinical examination, he had microcephaly, a low set of hair on the forehead, arched and confluent eyebrows, long eyelashes, a wide nose root, anteverted nostrils, a long and bulging philtrum, a mouth falling at the corners and a very thin upper lip, a low implantation of the ears and a microretrognatism. He was puny with a weight loss of -4 DS. Biologically, the infectious balance was negative.An abdominal ultrasound performed was without abnormalities as well as the transfontanellar ultrasound. A thoracic CT showed a large right mediastinal hilar cystic mass measuring $69 \times 68 \times 44 \mathrm{~mm}$ with fluid density and regular clean wall enhanced after injection of contrast agent dealing with a bronchogenic cyst. The therapeutic abstention was opted. The evolution was marked by the spontaneous regression of the cyst.

Conclusion Cornelia De Lange syndrome is rare with variable severity. The association with bronchogenic cyst which had spontaneously regressive evolution is a rare entity.

\section{P660 ABSCESS OF THE KIDNEY, A DIAGNOSIS NOT ALWAYS EVIDENT!}

Faiza Safi, Lamia Gargouri, Manel Hsairi, Chiraz Regaieg*, Bayen Maalej, Abdelmajid Mahfoudh. Hedi Chaker Hospital, Sfax, Tunisia

\subsection{6/archdischild-2019-epa.990}

Introduction Kidney abscess is defined as a suppurate lesion collected in the renal parenchyma. It is a rare pathology in pediatrics. We report four cases of renal suppuration.

Material and method This is a retrospective study over a period of 9 years (2010-2018) collaging all cases of renal abscess having been hospitalized in the pediatric ward, emergency and pediatric resuscitation of Sfax.

Results We collected 4 cases of renal abscess. These were two boys and two girls. The average age was $5 \frac{1}{2}$ years with extremes ranging from $3 \frac{1}{2}$ years to 10 years. The delay of diagnosis was estimated at an average of 19 days. Fever and 